\title{
Chlorpheniramine impairs functional recovery in Carassius auratus after telencephalic ablation
}

\author{
D.C. Garção, L. Canto-de-Souza, F. Romaguera and R. Mattioli \\ Laboratório de Neurociências, Departamento de Fisioterapia, Universidade Federal de São Carlos, \\ São Carlos, SP, Brasil \\ Correspondence to: R. Mattioli, Departamento de Fisioterapia, UFSCar, Rodovia Washington Luiz, \\ km 235, 13565-905 São Carlos, SP, Brasil \\ Fax: +55-16-3361-2081. E-mail: mattioli@ufscar.br
}

\begin{abstract}
We determined the effect of an $\mathrm{H}_{1}$ receptor antagonist on the functional recovery of Carassius auratus submitted to telencephalic ablation. Five days after surgery the fish underwent a spatial-choice learning paradigm test. The fish, weighing 6-12 g, were divided into four groups: telencephalic ablation (A) or sham lesion (S) and saline (SAL) or chlorpheniramine (CPA, ip, $16 \mathrm{mg} / \mathrm{kg})$. For eight consecutive days each animal was trained individually in sessions separated by $24 \mathrm{~h}$ (alternate days). Training trials (T1-T8) consisted of finding the food in one of the feeders, which were randomly blocked for each subject. Animals received an intraperitoneal injection of SAL or CPA 10 min after the training trials. The time spent by the animals in each group to find the food (latency) was analyzed separately at T1 and T8 by the Kruskal-Wallis test, followed by the Student Newman-Keuls test. At T1 the latencies (mean \pm SEM) of the A-SAL $(586.3 \pm 13.6)$ and A-CPA $(600 \pm 0)$ groups were significantly longer than those of the S-SAL (226.14 \pm 61.15$)$ and S-CPA (356.33 \pm 68.8$)$ groups. At T8, the latencies of the A-CPA group (510.11 \pm 62.2$)$ remained higher than those of the other groups, all of which showed significantly shorter latencies (A-SAL $=301.91 \pm 78.32$; S-CPA = $191.58 \pm 73.03$; S-SAL $=90.28 \pm 41$ ) compared with T1. These results support evidence that training can lead to functional recovery of spatial-choice learning in telencephalonless fish and also that the antagonist of the $\mathrm{H}_{1}$ receptor impairs it.
\end{abstract}

Key words: Functional recovery; Spatial-choice learning; Histamine; Chlorpheniramine; Carassius auratus; Telencephalic ablation Research supported by CNPq (\#300499/2004-3). Publication supported by FAPESP.

Received June 26, 2008. Accepted February 9, 2009

\section{Introduction}

Cerebral histamine is a biogenic monoamine that does not cross the blood brain barrier (1) and is present in mast cells and neurons of the central nervous system (CNS). Much research has been done to investigate the influences of the central histaminergic system (CHS) on CNS functions. Among them are circadian rhythm (2), anxiety (3-5), pain perception (6), locomotor activity modulation (7), learning and memory processes (8-11), synaptic plasticity, and CNS functional recovery (12-15).

In goldfish, the histaminergic cell bodies are present in the posterior part of the hypothalamus, adjacent to the third ventricle, a homologous region of the tuberomammilar nucleus (TMN) of mammals. This nucleus sends projections to the telencephalon, diencephalon, mesencephaIon, optic tectum, cerebellum, and spinal cord (16). $\mathrm{H}_{1}$ receptors are present also in the cerebellum, hippocampus, thalamus, hypothalamus, nucleus accumbens, amygdaloid nuclei, and optic tectum of teleostean fish (17). In addition, some studies have shown that telencephalic ablation causes deficits in the instrumental appetitive learning involving a delay of reinforcement $(18,19)$.

A recent study of mice lacking histamine $\mathrm{H}_{1}$ and $\mathrm{H}_{2}$ receptors indicated that the acquisition of a spatial memory in a Barnes maze test was impaired (20). This result indicates that histaminergic neurotransmission is involved in hippocampal synaptic plasticity. Another study indicated 
that histamine in the ventral hippocampus can improve MK-801-induced spatial memory deficits (21).

There is some evidence suggesting that the TMN acts as an inhibitory neural substrate to control reinforcement and mnemonic processes (22). The $\mathrm{CHS}$ seems also to be involved in neural plasticity and functional recovery following damage to the CNS. Piratello and Mattioli (14) suggest that the inhibition of the histaminergic system by chlorpheniramine accelerated the functional recovery process observed after hemilabyrinthectomy in goldfish but that the administration of L-histidine did not cause any effects compared to saline-treated animals. In another study, it was shown that the body tilt of animals treated with thioperamide decreased from the 13th day on, while the animals treated with saline presented a significant reduction on the 7th day of treatment. These data suggest that lower histamine levels delayed the process of functional recovery in goldfish (15).

In view of the involvement of the CHS in the functional recovery process, the aim of the present study was to investigate the effect of the blockade of the histaminergic receptor $\mathrm{H}_{1}$ on functional recovery of a spatial-choice learning task in Carassius auratus submitted to telencephalic ablation.

\section{Subjects and Methods}

\section{Subjects}

Forty-seven experimentally naive goldfish (C. auratus) obtained from a local supplier were kept in stock tanks for acclimatization for a minimum of three weeks before the beginning of the experiment. The fish were kept in aerated filtered water $\left(22 \pm 2^{\circ} \mathrm{C}\right)$ under a natural light cycle and were fed five times per week with flake food for ornamental fish (Super Red, Formosa).

The fish, weighing 6-12 g, were divided into groups of $10-15$ individuals and were housed in glass aquaria during recovery after surgery and throughout the experiment. During the recovery period, they were fed from PVC-made feeders similar to the ones used in the experimental aquaria (Fast Color, Formosa). During the experiment, the fish

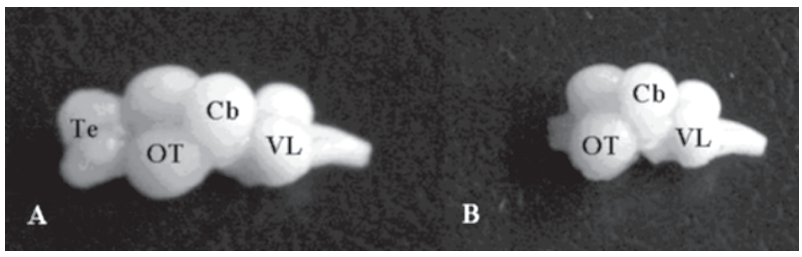

Figure 1. Upper view of a normal brain $(A)$ and of a brain with telencephalic ablation (B). Te = telencephalon; OT = optic tectum; $\mathrm{Cb}$ = cerebellum; VL = vagal lobe. received only the pellets (Fast Color) they obtained in the daily experimental session.

\section{Surgical procedure}

Before surgery, the goldfish were randomly divided into two groups, one of them subjected to telencephalon ablation $(\mathrm{N}=21)$ and the other to sham surgery without ablation $(\mathrm{N}=$ 26; Figure 1). Before the surgical procedures, the fish were anesthetized by immersion in $0.8 \mathrm{~g} / \mathrm{L}$ tricaine methanesulfonate (3-aminobenzoic acid ethyl ester methasulfonate; Sigma) until breathing ceased. Each fish was then placed in the surgical apparatus held in place by lateral holders and half immersed in water. An adjustable tube was inserted into the animal's mouth to ensure a constant flow of aerated water through the gills, with the concentration of anesthetic in the water reduced from 0.8 to $0.3 \mathrm{~g} / \mathrm{L}$ during surgery. The dorsal skin and skull were removed carefully with a drill under visual control to expose the brain. Both telencephalic lobes and the olfactory bulb were aspirated with a glass pipette connected to a manual vacuum system. After ablation, the skull was covered with fast drying dental cement (Acrílico Auto-Polimerizante Clássico, JET, Brazil, and Líquido Acrílico AutoPolimerizável, Dental VIPI Ltda., Brazil). Each fish was then placed in a glass aquarium for a recovery period of 5 days before the behavioral tests, since the surgical procedure initially reduced the locomotor activity of the animals. Nine animals of 21 died after the surgical procedure.

\section{Pharmacological treatment}

Chlorpheniramine maleate salt (CPA), an $\mathrm{H}_{1}$ receptor antagonist (Sigma), was dissolved in saline solution and used at the dose of $16 \mathrm{mg} / \mathrm{kg}$ body weight. This dose have been shown to be effective for fish in several models of learning and memory in our laboratory $(11,14,15)$. The saline solution was used as experimental control. The CPA and vehicle were blind-coded and injected intraperitoneally (ip) using a volume of $1 \mathrm{~mL} / \mathrm{kg}$ body weight. The drugs and saline were prepared before the experiment and were kept under refrigeration until the time of their use in coded tubes, so that the researcher was blind to their contents at the time of the experiments.

The fish submitted to telencephalic ablation were divided into two groups, one treated with $\mathrm{CPA}(\mathrm{A}-\mathrm{CPA}, \mathrm{N}=9$ ) and the other with saline ( $A-S A L, N=12)$. The fish submitted to sham surgery also received CPA (S-CPA, $N=12$ ) or saline ( $\mathrm{S}-\mathrm{SAL}, \mathrm{N}=14$ ).

\section{Apparatus}

A T-shaped glass aquarium was used. The "T" stem was $20 \mathrm{~cm}$ long and $11.5 \mathrm{~cm}$ wide and the cross bar was $35.5 \mathrm{~cm}$ long and $9.5 \mathrm{~cm}$ wide. Two PVC tubes $(5 \mathrm{~cm}$ long 
and $2.5 \mathrm{~cm}$ in diameter) were attached to the opposite ends of the cross bar, and served as feeders. The intersection of the " $T$ " was delimitated by a guillotine-like sliding door, which characterized the "T" stem as a start-chamber at the beginning of the experiment.

\section{Behavioral procedure}

The fish were deprived of food for $48 \mathrm{~h}$ prior to experiments in order to enhance their foraging activity. The behavioral procedure was performed on 10 consecutive days. On the first two days, an adaptation trial was performed for $10 \mathrm{~min}$. At the beginning, the fish were placed individually in the start chamber and confined there for 30 s. The sliding door was then raised, allowing the fish to swim through the entire aquarium. For adaptation, the fish were allowed to freely explore the maze and could access food from both feeders.

The training trials were started on the 3rd day and were repeated at $24-\mathrm{h}$ intervals between sessions. The feeders were the same throughout the training sessions for each fish. However, between animals, the feeders were randomly blocked with a thin net to block access to food and the fish was forced to swim to the opposite side until the end of the experiment.

Each fish was placed individually in the experimental aquarium start chamber. After $30 \mathrm{~s}$ the sliding door was raised, and the fish was allowed to swim freely throughout the aquarium for $10 \mathrm{~min}$ or until it found the food. If the food was found, the fish was allowed to feed for $2 \mathrm{~min}$. The time spent to reach the food (latency) was recorded in seconds. The training sessions were limited to $10 \mathrm{~min}$ because a strong decrease in foraging activity was reported in earlier experiments after this time (23). At the end of each trial, the fish was removed from the apparatus and returned to its home aquarium.

Beginning with the first trial, the fish were injected ip every 2 days with CPA or vehicle $10 \mathrm{~min}$ after their return to the home aquarium. This period is compatible with the 1-h time window of memory consolidation for fish reported by Liu and Braud (24).

\section{Statistical analysis}

The results were initially submitted to the Levene test to verify homogeneity $(P>0.05)$. Since the data were not homogeneously distributed, a nonparametric test was applied. The mean latencies of the four groups during the first and last trial (T1 and T8) were analyzed separately by the Kruskal-Wallis test $(P<0.05)$. In order to observe the effect of each variable, the results were then submitted to the Student-Newman-Keuls (SNK) multiple comparison test $(P<0.05)$.

\section{Results}

The mean latencies ( \pm SEM) are reported in Figures 2 and 3 . In the first trial, before the pharmacological treatment, the mean latencies of telencephalonless fish (586.33 \pm 13.6 and $600 \pm 0$ ) were significantly longer than those of shamoperated fish (226.14 \pm 61.15 and $356.33 \pm 68.8)$, indicating a deficit in localizing the food source $(P<0.01$, KruskalWallis; $P<0.05$, Student-Newman-Keuls; Figure 2).

At the end of the experiment, similar latencies were observed for the S-SAL $(90.28 \pm 41)$, S-CPA (191.58 \pm 73.03) and A-SAL (301.91 \pm 78.32) groups $(P>0.05$, Kruskal-Wallis; $P>0.05$, Student-Newman-Keuls; Figure 3 ), suggesting a recovery from the deficit induced by the lesion for the saline group. Additionally, functional recovery seemed to be impaired in the A-CPA $(510.11 \pm 62.2)$ group since this group showed significantly longer latency when compared with S-SAL $(P<0.01$, Kruskal-Wallis; $P<$ 0.05, Student-Newman-Keuls).

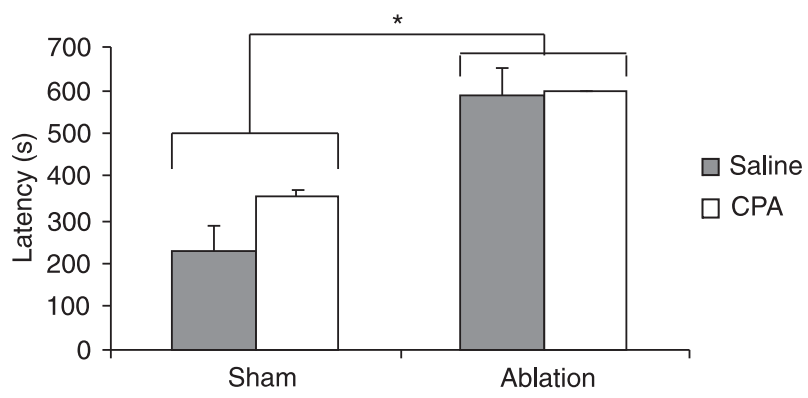

Figure 2. Latencies of the sham-operated $(S)$ and telencephalic ablation (A) groups in trial number 1. Data are reported as means \pm SEM. S-SAL group $(N=14), S-C P A(N=12), A-S A L(N=14)$, and $\mathrm{A}-\mathrm{CPA}(\mathrm{N}=9)$. $\mathrm{SAL}=$ saline; $\mathrm{CPA}=$ chlorpheniramine. ${ }^{*} \mathrm{P}<$ 0.05 compared to the S-SAL and S-CPA groups (Student-Newman-Keuls test).

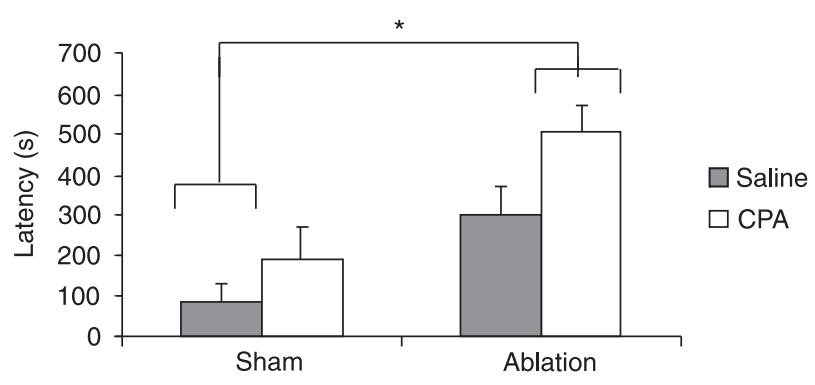

Figure 3. Latencies of the sham-operated (S) and telencephalic ablation (A) groups in the final trial (number 8). Data are reported as means \pm SEM. S-SAL group $(N=14)$, S-CPA $(N=12)$, A-SAL $(N=14)$, and $A-C P A(N=9)$. $S A L=$ saline; $C P A=$ chlorpheniramine. ${ }^{*} P<0.05$ compared to the S-SAL group (Student-Newman-Keuls test). 


\section{Discussion}

Functional recovery after lesion depends on the ability of the organism to relearn or to compensate for a behavior (9). Some studies indicate that the CHS has an important role in the synaptic plasticity and CNS functional recovery, but these data are controversial. Piratello and Mattioli $(14,15)$ showed that the CPA accelerated the functional recovery process in fish after a vestibular system lesion, while Weiler et al. (12) found that a central injection of histidine accelerated recovery in mice after unilateral lesion in the TMN region. The blockade of histamine $\mathrm{H}_{1}$ receptors may play a role in spatial cognition, impairing the acquisition of memory in rats evaluated in an 8-arm radial maze (25). However, the post-trial application of $\mathrm{H}_{1}$ receptor antagonists to goldfish improved learning in a spatial task (23). In the present study, the injection of CPA per se did not impair the acquisition of a reinforced spatial-choice learning task since the S-CPA group learned the task and reached latencies similar to those of the S-SAL group after training. Nevertheless, when coupled with telencephalon removal, CPA seems to impair functional recovery. Alternatively, we may assume that the action of CPA is mediated by telencephalic structures in goldfish.

Our data showed that training could lead to functional recovery because both groups (ablated or not) attained similar latencies after eight training trials, suggesting that telencephalon removal impairs the performance in reinforced spatial-choice learning tasks, but does not block the acquisition of the task proposed. Earlier findings have suggested that simple instrumental learning was not affected by telencephalon removal $(26,27)$; however, there is some evidence that a temporal memory system is involved in spatial learning at the telencephalon level since dorsolateral lesion of this structure impaired spatial learning (28). Another study proposed that this structure has an important role in short-term memory in goldfish (29).

We observed that removal of the telencephalon impairs the behavioral performance in the proposed task since telencephalonless fish had higher latencies in T1 and T8 when compared with sham animals. These data indicate an important role of the telencephalon for the acquisition of the task, but it seems that this structure is not essential for this process. This suggestion is based on the fact that, albeit with a delay, the lesioned animals were able to learn regardless of CPA treatment, since A-SAL and A-CPA did not differ in the last trial. Therefore, these results support the hypothesis that the telencephalon contributes to this process by facilitating the integration of neural events with extra-telencephalic areas involved in spatial-choice learning tasks.
The histaminergic fibers of the telencephalon seem to be necessary for the spatial-choice learning task. However, the role of these fibers appears to be supplemented by mesencephalic structures since S-CPA fish acquired the task and A-CPA fish did not. This finding leads us to agree with the hypothesis that CPA does not operate exclusively in the telencephalon and is able to act on primitive cerebral structures, amongst them the cerebellum (5). A previous study using an autoradiographic method to identify the distribution of histamine receptors indicated that the $\mathrm{H}_{1}$ histaminergic receptors are predominant in the cerebellum of teleost fish (17). Additionally, Vonderschen et al. (30) reported the existence of direct connections between the cerebellum and the telencephalon (cerebellar-hypothalamic pathways), which may constitute a communication pathway involved in the coordination of non-motor tasks, such as spatial memory tasks (31).

Another study also describes the presence of $\mathrm{H}_{1}$ receptors at the cerebellum, suggesting that histamine is involved in the signal transmission from the hypothalamus to the cerebellum (32). In rats, histamine has an excitatory action on the spontaneous firing of cerebellar cortical in the granule cell, suggesting that the cerebellar-hypothalamic histaminergic fibers may play an important role in cerebellar functions (33).

Therefore, considering the role of the cerebellum in motor behavior, a putative mechanism for CPA action on the CNS is the mediation of cerebellar motor learning (histaminergic cerebellar pathway). Studies have suggested that learning processes involve molecular and cellular mechanisms such as long-term potentiation and its metabolic intra-neuronal paths, analogous to neuronal plasticity (34). It has been suggested that the adaptive process of the organism after a lesion, also known as functional recovery, also involves these mechanisms. Therefore, it is reasonable to infer that the learning of a new task may be indicative of functional recovery (12). Thus, our data support the hypothesis of an action of CPA on functional recovery in structures other than the telencephalon, which is involved in spatial learning, probably through the hypothalamus, optic tectum and/or cerebellum.

The results obtained in this study support the view that training can lead to functional recovery of spatial-choice learning in telencephalonless fish, and that the antagonist of the $\mathrm{H}_{1}$ receptor impairs functional recovery.

\section{Acknowledgments}

We would like to thank Teresa de Fátima Fatori Piassi for technical assistance. 


\section{References}

1. Watanabe T, Taguchi Y, Shiosaka S, Tanaka J, Kubota H, Terano $\mathrm{Y}$, et al. Distribution of the histaminergic neuron system in the central nervous system of rats; a fluorescent immunohistochemical analysis with histidine decarboxylase as a marker. Brain Res 1984; 295: 13-25.

2. Burns TA, Huston JP, Spieler RE. Circadian variation of brain histamine in goldfish. Brain Res Bull 2003; 59: 299301.

3. Imaizumi M, Onodera K. The behavioral and biochemical effects of thioperamide, a histamine H3-receptor antagonist, in a light/dark test measuring anxiety in mice. Life Sci 1993; 53: 1675-1683.

4. Santos NR, Huston JP, Brandao ML. Blockade of histamine $\mathrm{H} 2$ receptors of the periaqueductal gray and inferior colliculus induces fear-like behaviors. Pharmacol Biochem Behav 2003; 75: 25-33.

5. Faganello FR, Mattioli R. Anxiolytic-like effect of chlorpheniramine in inhibitory avoidance in goldfish submitted to telencephalic ablation. Prog Neuropsychopharmacol Biol Psychiatry 2007; 31: 269-274.

6. Izadi Mobarakeh J, Nalwalk JW, Watanabe T, Sakurada S, Hoffman M, Leurs R, et al. Improgan antinociception does not require neuronal histamine or histamine receptors. Brain Res 2003; 974: 146-152.

7. Alvarez XA, Franco A, Fernandez-Novoa L, Cacabelos R. Effects of neurotoxic lesions in the posterior hypothalamic region on psychomotor activity and learning. Agents Actions 1994; 43: 21-23.

8. de Almeida MA, Izquierdo I. Memory facilitation by histamine. Arch Int Pharmacodyn Ther 1986; 283: 193-198.

9. Mattioli R, Nelson CA, Huston JP, Spieler RE. Conditioned place-preference analysis in the goldfish with the $\mathrm{H} 1$ histamine antagonist chlorpheniramine. Brain Res Bull 1998; 45: 41-44.

10. Medalha CC, Coelho JL, Mattioli R. Analysis of the role of histamine in inhibitory avoidance in goldfish. Prog Neuropsychopharmacol Biol Psychiatry 2000; 24: 295-305.

11. Cofiel LP, Mattioli R. Involvement of histamine receptors in the acquisition of inhibitory avoidance in Carassius auratus. Prog Neuropsychopharmacol Biol Psychiatry 2006; 30: 1246-1250.

12. Weiler HT, Wagner U, Huston JP. Unilateral lesion in the tuberomammillary nucleus region: behavioral asymmetries and effects of histamine precursor. Behav Brain Res 1992; 49: 167-173.

13. Passani MB, Giannoni $P$, Bucherelli $C$, Baldi E, Blandina $P$. Histamine in the brain: beyond sleep and memory. Biochem Pharmacol 2007; 73: 1113-1122.

14. Piratello AC, Mattioli R. Effects of chlorpheniramine and Lhistidine on vestibular compensation in goldfish, Carassius auratus. Neurosci Lett 2004; 367: 160-163.

15. Piratello AC, Mattioli R. Thioperamide delays vestibular compensation in goldfish. Neurosci Lett 2007; 415: 146-148.

16. Inagaki N, Panula $P$, Yamatodani A, Wada H. Organization of the histaminergic system in the brain of the teleost, Trachurus trachurus. J Comp Neurol 1991; 310: 94-102.

17. Choich JA, El-Nabawi A, Silbergeld EK. Evidence of histamine receptors in fish brain using an in vivo $\left[{ }^{14} \mathrm{C}\right] 2$-deoxyglucose autoradiographic method and an in vitro receptor- binding autoradiographic method. Environ Res 2004; 94: 86-93.

18. Savage GE. Telencephalic lesions and avoidance behaviour in the goldfish (Carassius auratus). Anim Behav 1969; 17: 362-373.

19. Savage GE, Swingland IR. Positively reinforced behaviour and the forebrain in goldfish. Nature 1969; 221: 878-879.

20. Dai $H$, Kaneko K, Kato $H$, Fujii $S$, Jing $Y, X u A$, et al. Selective cognitive dysfunction in mice lacking histamine $\mathrm{H} 1$ and $\mathrm{H} 2$ receptors. Neurosci Res 2007; 57: 306-313.

21. Xu LS, Yang LX, Hu WW, Yu X, Ma L, Liu LY, et al. Histamine ameliorates spatial memory deficits induced by MK-801 infusion into ventral hippocampus as evaluated by radial maze task in rats. Acta Pharmacol Sin 2005; 26: 1448-1453.

22. Huston JP, Wagner U, Hasenohrl RU. The tuberomammillary nucleus projections in the control of learning, memory and reinforcement processes: evidence for an inhibitory role. Behav Brain Res 1997; 83: 97-105.

23. Spieler RE, Nelson CA, Huston JP, Mattioli R. Post-trial administration of $\mathrm{H} 1$ histamine receptor blocker improves appetitive reversal learning and memory in goldfish, Carassius auratus. Neurosci Lett 1999; 277: 5-8.

24. Liu Y, Braud WG. Modification of learning and memory in goldfish through the use of stimulant and depressant drugs. Psychopharmacologia 1974; 35: 99-112.

25. Chen Z, Chen JQ, Kamei C. Effect of H1-antagonists on spatial memory deficit evaluated by 8 -arm radial maze in rats. Acta Pharmacol Sin 2001; 22: 609-613.

26. Hollis $\mathrm{KL}$, Overmier JB. The function of the teleost telencephalon in behaviour: a reinforcement mediator. In: Mostofsky DI (Editor), The behaviour of fish and other aquatic animals. New York: Academic Press; 1978. p 137195.

27. Overmier JB, Curnow PF. Classical conditioning, pseudoconditioning, and sensitization in "normal" and forebrainless goldfish. J Comp Physiol Psychol 1969; 68: 193-198.

28. Portavella M, Vargas JP, Torres B, Salas C. The effects of telencephalic pallial lesions on spatial, temporal, and emotional learning in goldfish. Brain Res Bull 2002; 57: 397-399.

29. Ohnishi K. Effects of telencephalic ablation on short-term memory and attention in goldfish. Behav Brain Res 1997; 86: 191-199.

30. Vonderschen K, Bleckmann $\mathrm{H}$, Hofmann MH. A direct projection from the cerebellum to the telencephalon in the goldfish, Carassius auratus. Neurosci Lett 2002; 320: 3740.

31. Zhu JN, Yung WH, Kwok-Chong CB, Chan YS, Wang JJ. The cerebellar-hypothalamic circuits: potential pathways underlying cerebellar involvement in somatic-visceral integration. Brain Res Rev 2006; 52: 93-106.

32. Takemura M, Kitanaka N, Kitanaka J. Signal transduction by histamine in the cerebellum and its modulation by $\mathrm{N}$ methyltransferase. Cerebellum 2003; 2: 39-43.

33. Li WC, Tang $\mathrm{XH}$, Li HZ, Wang JJ. Histamine excites rat cerebellar granule cells in vitro through $\mathrm{H} 1$ and $\mathrm{H} 2$ receptors. J Physiol 1999; 93: 239-244.

34. Kandel ER, Schwartz JH, Jessell TM. Principles of neural science. 4th edn. New York: McGraw-Hill; 2004. 